\title{
Política e decadência: O envolvimento crítico de Nietzsche com a modernidade européia*
}

\author{
Daniel Conway**
}

\begin{abstract}
Resumo: $\mathrm{O}$ artigo tem por objetivo investigar a presença de um realismo político no pensamento de Nietzsche, assim como analisar as relações existentes entre esse realismo e um modelo de natureza preconizado pelo filósofo.
\end{abstract}

Palavras-chave: política - decadência - modernidade - realismo

Ainda que seletivo, Nietzsche foi ávido estudante de história da política. Enquanto se familiarizava com uma série de tradições e escolas, costumava se alinhar Aos principais expoentes do que ele chamava de realismo. Era com orgulho que reconhecia as influências de Tucídides, Maquiavel e Goethe, ao mesmo tempo em que aplaudia as façanhas de Manu, César, Pilatos e Napoleão. Em enunciado que bem caracteriza suas simpatias realistas, celebrava Napoleão como "ens realissimum" e elogiava Goethe por se manter um "convicto realista" em plena "era de propensões irreais" (GD/CI, Incursões de um extemporâneo 49, KSA 6.151-152). Postando-se

\footnotetext{
* Este artigo é um recorte de um trabalho mais extenso intitulado "The Birth of the State", publicado em SIEMENS, H.; ROODT, V. (orgs.). Nietzsche, Power and Politcs. Rethinking Nietzsche's Legacy for Political Thought. Berlim, Nova York: Walter de Gruyter, 2008, p. 37-67. Agrademos a editora a cessão dos direitos autorais para a publicação das páginas 37-45 neste volume dos Cadernos Nietzsche. Tradução de Saulo Krieger.

** Professor do Departamento de Filosofia e Humanidades da Texas A\&M University, Estados Unidos. E-mail: conway@philosophy.tamu.edu.
} 
em controversa oposição a Sócrates e Platão, identificava "a civilização dos sofistas" como sendo "a civilização dos realistas" (GD/ CI, O que devo aos antigos, 2, KSA 6.155-156). Com base nessas e em outras manifestações de solidariedade a predecessores realistas, encontramos uma justificativa para supor que Nietzsche esposou uma versão de realismo político. Como veremos, porém, sua compreensão de realismo político diverge significativamente de abordagens mais conhecidas dessa posição, já que ele não acreditava que o poder necessariamente fizesse melhorar as coisas ${ }^{1}$.

Como bem se pode esperar de um realista, Nietzsche via como seus antípodas todos aqueles que insistiam em abordar a política de uma distância confortável, que ele associava a um idealismo. Em vez de tratar dos seres humanos e suas entidades políticas em sua realidade demasiado humana, os idealistas preferem teorizar e legislar em favor de seres irreais e atemporais, e de configurações utópicas que eles supostamente ocupam. Como paradigmático dessa distinção entre realismo e idealismo, ele cita o contraste entre Tucídides e Platão:

Tucídides e, talvez, o Príncipe de Maquiavel são aparentados ao máximo a mim próprio pela vontade incondicionada de não se simular nada e ver a razão na realidade - e não na "razão", e menos ainda na “moral" [...] Tucídides como a grande suma, a grande revelação daquela forte, rigorosa, dura fatualidade que estava no instinto dos helenos antigos. O ânimo diante da realidade distingue em última instância naturezas tais como Tucídides e Platão: Platão é um covarde diante da realidade - consequentemente, refugia-se no ideal; Tucídides se tem em seu poder - consequentemente, tem também as coisas em seu poder... (GD/CI, O que devo aos antigos, 2, KSA 6.155-156. Trad. Rubens Rodrigues Torres Filho).

1 Para elucidativos debates sobre a relação de Nietzsche com o realismo político, ver SHAW, T. Nietzsche's Political Skepticism. Princeton, NJ: Princeton University Press, 2007; LEITER, B. Nietzsche on Morality. London: Routledge, 2001, p. 48-51. 
A coragem é exigida, presume-se, porque um confronto inflexível com a realidade provavelmente revelará algumas verdades desagradáveis sobre política — todas as quais a Nietzsche apraz celebrar. $\mathrm{O}$ objetivo da política, em primeiro lugar, é dar apoio à produção e ao avanço da cultura, já que somente a cultura pode justificar a existência humana - e desse modo garantir o futuro da humanidade - mediante uma "valorização do tipo humano" (JGB/ BM 257, KSA 5.205-206). De acordo com Nietzsche, isso significa que os legisladores deveriam promover o surgimento desses seres humanos exemplares, cujos exóticos labores de autoperfeição inspiram outros a, por sua vez, se aperfeiçoarem. Consequentemente, ele atribui à política um estatuto subordinado e um valor estritamente instrumental ${ }^{2}$. Em caso algum, Nietzsche insiste, a política deveria ser considerada um fim em si mesma.

O problema com a política contemporânea, ele observa, é que o moderno Estado-nação contenta-se simplesmente com se perpetuar. Não reconhece nenhum objetivo — muito menos o de produzir cultura - acima e além de seu serviço para si mesmo. $\mathrm{O}$ exemplo mais pertubador desse problema é a Alemanha de Bismarck, na qual os defensores autossatisfeitos faziam valer a adequação de qualquer simulacro de cultura que o Reich viesse a apoiar. Ao declarar o fracasso do moderno Estado-nação, Nietzsche observa que "a cultura e o Estado — não haja engano a respeito disso — são antagonistas: 'Estado cultural' é apenas uma ideia moderna. Um vive do outro, um prospera à custa do outro. Todas as grandes épocas da cultura são tempos de declínio político: o que é grande no sentido cultural é apolítico, mesmo antipolítico." (GD/CI, O que falta aos alemães, 4, KSA 6.106-107) É nessa passagem que Nietzsche mais diretamente se distancia do padrão "o poder tem sempre razão" como articulação do realismo político. Falando explicitamente aos alemães,

2 Cf. DETWILER, B. Nietzsche and the Politics of Aristocratic Radicalism. Chicago: University of Chicago Press, 1982, p. 66-67. 
ele chega a propor o seu próprio slogan, que se opõe ao primeiro: o poder imbeciliza... [die Macht verdummt] (GD/CI, O que falta aos alemães, 1, KSA 6.103-104). O poder tem sempre razão, acreditava ele, somente no caso de ele impor a manutenção de um aparato político dedicado à produção e ao avanço da cultura. Por si só, o acúmulo de poder político-militar não justifica nada. De fato, quando não se tem em vista nenhuma finalidade cultural mais elevada, o acúmulo de poder político-militar realmente se faz sintomático de uma decadência cultural.

Em segundo lugar, mesmo sob as melhores circunstâncias, não é muito o que se pode fazer pela maioria dos seres humanos. O "pau torto" da humanidade não produz de pronto uma forma que seja indicativa de beleza, de força ou de autocontrole. Contudo, isso não significa que o realista político seja obrigado a simplesmente tomar os seres humanos tal qual os encontra. Muito mais, ele deve legislar olhos postos no que um povo ou nação ou casta pode realisticamente se tornar. Se ele julgar um povo, nação ou casta receptivos à produção de genuína cultura, esse objetivo terá de ser alcançado tão só pela imposição de estrutura e forma durante um período prolongado de incansáveis esforços (GD/CI, Incursões de um extemporâneo 39, KSA 6.140-142). Se o político tiver como objetivo, como ele deve ter, a produção e o avanço da cultura, os legisladores estarão dispostos a empregar os meios e medidas mais iliberais à sua disposição. Conforme Nietzsche explica em passagem frequentemente citada: “Toda elevação do tipo 'homem’ foi, até o momento, obra de uma sociedade aristocrática [...] que acredita numa longa escala de hierarquias e diferenças de valor entre um e outro homem, e que necessita da escravidão em algum sentido" (JGB/BM 257, KSA 5.205-206).

Para Nietzsche, a atração exercida por uma sociedade aristocrática está em ela tornar um legislador cioso capaz de prover simultaneamente o progresso e o aperfeiçoamento de diversos em geral três — diferentes tipos humanos, cada qual de uma casta ou classe separada. Uma sociedade aristocrática bem concebida, 
sugere ele, pode até mesmo acomodar alguma versão de moralidade cristã em seu estrato mais baixo (AC/AC 58, KSA 6.245-247), contanto que padres, a quem ele acusa de incitar a revolta do escravo na moralidade, sejam tratados como párias (GD/CI, Incursões de um extemporâneo, 45, KSA 6.146-148) ${ }^{3}$.

Em terceiro lugar, a liberdade política é alcançada não mais como uma questão de decreto legislativo, muito menos de direito natural, mas somente em resposta a obstáculos estrategicamente colocados no caminho do desenvolvimento do povo, nação ou casta em questão. A liberdade, acreditava Nietzsche, é mais bem compreendida como uma conquista, garantida apenas por meio da luta prolongada contra forças antagonistas. ${ }^{4}$ Ele explica que

[A liberdade é medida] segundo a resistência que tem de ser superada (...). Os povos que valeram algo, que adquiriram valor, não o adquiriram sob instituições liberais: o grande perigo fez deles algo digno de veneração (...). Aquelas grandes estufas para a espécie forte, para a mais forte espécie de home que houve até agora, as comunidades aristocráticas ao modo de Roma e Veneza, entendiam liberdade exatamente no sentido em que eu entendo a palavra liberdade: como algo que se tem e não se tem, que se quer, e que se conquista..." (GD/CI, Incursões de um extemporâneo, 38, KSA 6.139-140. Trad. Rubens Rodrigues Torres Filho).

3 Ao seu "Decreto contra a cristandade", que Nietzsche pode ter pretendido de algum modo anexar a $O$ anticristo(ão), sem ter conseguido encaminhar para impressão antes de seu colapso em Turim, em 1889, ele inclui a seguinte proposição: “O sacerdote é nosso chandala - ele deveria ser condenado, morrer de fome, ser conduzido a todo tipo de ermo (trad. ingl. de Shapiro 1989 146).

4 Cf. OWEN, D. Nietzsche, Politics and Modernity. London: Sage Publications, 1995, p. 16469; SIEMENS, H. "Nietzsche contra Liberalism on Freedom". In: PEARSON, K. (org.). A Companion to Nietzsche. London: Blackwell Publishing, 2006, p. 449-451. 
Assim, um legislador que realmente deseje valorizar a liberdade de seu povo é obrigado a planejar instituições que desafiarão o seu povo a transcender suas limitações aparentemente "naturais". Ocorre que esse objetivo não é alcançado, observa Nietzsche, por instituições que simplesmente garantam a liberdade a todos os interessados. Cada casta ou classe em uma sociedade aristocrática tem de ser provida de um conjunto único de resistências, especialmente destinadas a maximizar o desenvolvimento do tipo humano a que são atribuídas. Além do mais, em cada caso essas resistências não devem ser nem muito exigentes, ou o povo ou o tipo perderá o ânimo e abandonará a sua busca de autoperfeição, nem por demais lenientes, ou o povo ou tipo em questão não alcançará sua plena potencialidade. Ou seja, o legislador tem de ser cuidadoso a fim de vislumbrar, para cada classe ou casta, o risco preciso que fará aflorar o melhor em cada tipo humano.

Em quarto lugar, as opções políticas disponíveis a qualquer povo, nação ou casta são ademais limitadas pela disposição histórica dos recursos que lhes são disponíveis. No que tange ao legislador, de fato muito reside na condição de o povo, a nação ou a casta em questão compartilhar uma tendência de movimento ascendente — isto é, para o crescimento, para saúde e força crescente - ou descendente - isto é, para a decadência, degeneração e força declinante. Períodos de ascendência e crescimento, os quais Nietzsche associa com a afirmação de forças ativas e nobres, serão relativamente breves e intensos, enquanto períodos de decadência, que o filósofo associa com o reino das forças reativas e servis, serão relativamente longos e sem inspiração. Por isso, no que diz respeito à criação de políticas, regimes e instituições, o legislador aspirante deverá estar preparado para honestamente calcular o lugar de seu povo no âmbito do ciclo histórico de crescimento e decadência, e calibrar seus projetos de acordo com isso. Não será o caso de fingir que um povo declinante pode ser capaz de responder produtivamente a instituições iliberais que conduzam à ascendência e ao crescimento, como seria loucura supor que instituições 
não intrusivas, "liberais", pudessem obter o melhor de uma nação, povo ou casta em ascensão. Como o filósofo observa, "as instituições liberais deixam de ser liberais logo que são alcançadas: não há, depois, nada tão radicalmente prejudicial à liberdade quanto às instituições liberais" (GD/CI, Incursões de um extemporâneo, 38, KSA 6.140-142) Conforme veremos, um alvo preferido da crítica, tomada em sentido mais amplo, de Nietzsche à modernidade é a crença esperançosa e fátua de que instituições liberais possam contribuir para a produção de cultura e para a valorização da humanidade. Elas não o podem; porém nós, modernos tardios, não estamos em condições de nos submeter ao tipo de instituições que mais provavelmente o fariam.

Em quinto lugar, o realista político tem de estar preparado para reconhecer que em algumas épocas, como a da modernidade tardia, nada de interessante pode ser feito de uma nação, povo ou casta particular. Em épocas assoladas pela decadência, nenhuma das opções políticas familiares pode ser exitosa em promover a produção da cultura. Em uma passagem cuja intenção é transmitir sua "crítica à modernidade" no sentido mais amplo, Nietzsche observa que "o Ocidente inteiro não tem mais os instintos de que nascem as instituições, de que nasce futuro: talvez nada contrarie tanto o seu "espírito moderno" [...] O que de instituições faz instituições é desprezado, odiado, rejeitado: acredita-se correr o perigo de uma nova escravidão, tão logo a palavra "autoridade" seja ouvida. (GD/CI, Incursões de um extemporâneo, 39, KSA 6.140-142). As instituições de que necessitamos são precisamente as que não podemos ter e que jamais aceitaríamos. É por isso, conclui Nietzsche, que nenhuma das opções políticas que tradicionalmente têm contribuído para o avanço da cultura continua viável na modernidade tardia. ${ }^{5}$ Carecendo dos "instintos a partir dos quais as instituições crescem", sendo realistas não podemos esperar prosperar sob o tipo de aparato político que

5 Quanto a esse aspecto, estou em dívida com DETWILER, B., op. cit., p. 83-97. 
nos moldaria em uma sociedade autêntica: "O que doravante não será mais construído, não mais pode ser construído, é — uma sociedade [Gesellschaft] no velho sentido da palavra; para construir tal edifício falta tudo, a começar pelo material. Nós todos já não somos material para uma sociedade" (FW/GC 356, KSA 3.597-602). Revela-se, pois, que as únicas instituições que nós, modernos tardios, somos capazes de sustentar são as instituições liberais que Nietzsche associa com escárnio à disseminação da democracia, esta que ele vê não como forma alternativa de governo, mas como "forma de declínio do poder organizador" (GD/CI, Incursões de um extemporâneo, 39, KSA 6.140-142) ${ }^{6}$. Mas se ele tem uma série de aspectos depreciativos a apontar nas instituições liberais (cf. GD/CI, Incursões de um extemporâneo, 37-43, KSA 6.136-144), o principal fracasso político dessas instituições está em serem incapazes de sustentar a produção e o avanço da cultura. Como tais, elas são incapazes de contribuir diretamente para a melhoria do tipo humano.

Em épocas como a modernidade tardia, tem-se a impressão de que só o que o realista político pode fazer é dar tempo ao tempo, para que a decadência percorra o seu curso natural. Nem mesmo o mais criativo e heroico dos legisladores é capaz de produzir cultura autêntica a partir das magras fontes disponíveis em uma época decadente. Como Nietzsche sussurra aos "conservadores" entre seus potenciais leitores, "não adianta: há que ir adiante, quero dizer, passo a passo adiante na décadence (— eis a minha definição do moderno 'progresso'...). Pode-se estorvar esse desenvolvimento e, mediante esse estorvo, represar, recolher, tornar mais veemente e mais súbita a degeneração mesma: mais não é possível fazer" (GD/ CI, Incursões de um extemporâneo, 43, KSA 6.144).

Essa compreensão da décadence pode explicar por que Nietzsche tende a atribuir um valor amplamente instrumental aos povos e nações (decadentes) da Europa do final do século dezenove.

6 Cf. HATAB, L. A Nietzschean Defence of Democracy. Chicago: Open Court, 1995, p. 29-42. 
O melhor que se pode dizer sobre tais povos e nações é que eles proverão os legisladores do futuro com uma massa flexível e homogênea, na qual uma nova forma poderá ser estampada à força. A continuarem as tendências atuais rumo à "democratização", Nietzsche prediz, "a impressão geral causada por esses futuros europeus será, provavelmente, a de trabalhadores bastante utilizáveis, necessitados do senhor, do mandante, como do pão de cada dia" (JGB/BM 242, KSA 5.182-183).

Enquanto os leitores de Nietzsche provavelmente recusarão tal abordagem deflacionária das opções políticas disponíveis aos povos e nações da Europa moderna tardia, ele é surpreendentemente otimista quanto ao papel legislativo que ele pode desempenhar, conduzindo a época moderna tardia a um acabamento oportuno e explosivo. Muito embora careça de acesso aos "materiais" que dariam sustentação à estrutura piramidal de uma sociedade aristocrática, baseada em castas, ele se encontra historicamente posicionado para inaugurar a era extramoral da grande política, na qual nada menos do que o futuro da terra será determinado. Aliás, ao se apresentar a si mesmo como um "destino", o filósofo explica:

Pois quando a verdade sair em luta contra a mentira de milênios, teremos comoções, um espasmo de terremotos, um deslocamento de montes e vales como jamais foi sonhado. A noção de política estará então completamente dissolvida em uma guerra dos espíritos, todas as formações de poder da velha sociedade terão explodido pelos ares todas se baseiam inteiramente na mentira: haverá guerras como ainda não houve sobre a Terra. Somente a partir de mim haverá grande política na Terra (EH/EH, Por que sou um destino, 1, KSA 6.365-366).

De que modo podemos equacionar essa abordagem grandiosa do "destino" de Nietzsche com seu inventário desalentador de opções políticas disponíveis na modernidade tardia? O importante aqui é a ênfase incomum que ele confere à situação histórica específica - e que encontra sua mais notável definição na "morte de Deus" 
—, na qual ele "com serenidade" se encontra (FW/GC343, KSA 3.573-574). Em razão das oportunidades sem precedentes que lhe foram conferidas por sua posição histórica única, como ele explica algures (FW/GC 357, KSA. 3.597-602, GM/GM III 27, KSA 5.408411), o simples ato de contar a verdade acerca da moralidade cristã desencadeará um bombardeio de convulsões e calamidades. Ele é um "destino" à medida que ocupa um nódulo de transformação da história mundial, onde a posse da verdade — que é seu legado como "bom europeu" (GM/GM III 27, KSA 5.408-411) — põe-no em discordância com tudo o que é erigido sobre as mentiras que deram sustentação ao avanço da civilização europeia. De acordo com Nietzsche, na verdade ele tem ao mesmo tempo a oportunidade e o dever de declarar guerra a tudo o que até então foi saudado como verdadeiro e bom. Todo expectativas quanto a cindir a história da civilização europeia em duas, e anuncia, "eu não sou um homem, sou dinamite" (EH/EH, Por que sou um destino, 1, KSA 6.365-366).

A despeito dos modestos recursos que tem à disposição, Nietzsche está preparado para iniciar a sequência final da autoanulação da moralidade cristã (GM/GM III 27, KSA 5.408-411). À medida que ele conduzir a época decadente da modernidade tardia a um acabamento oportuno e que se esgote em si mesmo, também conduzirá a um fim o período moral na história do desenvolvimento humano. Como resultado desses esforços em dizer a verdade, ou assim Nietzsche antecipa, os que prevalecerem nas terríveis guerras que estão por vir não se vincularão nem por precedente histórico, nem por fronteiras geopolíticas, nem pela moralidade cristã, nem por crença religiosa, tampouco pela fé na verdade em si. Serão livres para participar à terra uma nova direção e um novo sentido. Os vitoriosos nessas guerras reconstruirão a cultura, enquanto, presumivelmente, nesse processo procederão a uma reengenharia do ser humano. Se esses novos senhores da terra se mostrarem inclinados a rastrear seu domínio global até seu labor histórico de contar a verdade, e Nietzsche prediz que o farão, ele terá "nascido postumamente" como instigador da era da "grande política". 
Como demonstra esta breve introdução, o realista nietzschiano tem de ser exímio observador da natureza no amplo espectro de suas encarnações humana e não humana. Ao adequar nomos a physis, o realista tem de proceder com um sentido claro e preciso quanto ao que a natureza acomodará (e não acomodará) em qualquer caso particular. Em particular, como vimos, o realista tem de assistir de perto ao ciclo natural de crescimento e decadência, este que determina o espectro de opções políticas viáveis em qualquer tempo para qualquer pessoa, nação ou casta tomada individualmente. Contudo, o que a natureza deverá acomodar não é nem estático nem uniforme. Ao contrário dos reducionistas niilistas-mecanicistas entre seus contemporâneos (GM/GM II 12, KSA 5.313-316), Nietzsche via a natureza como força ativa, dinâmica, plástica e criativa. ${ }^{7} \mathrm{Na}$ abundância de suas acomodações, acreditava ele, a natureza exibe tendências criativas que reúnem propósito e desígnio.

A bem da verdade, na maioria dos casos, atribuições de propósito e desígnio à natureza redundam em nada mais do que projeções fáceis, nascidas do "orgulho" e "arrogância" que encorajaram os estoicos a descobrir o cânone de sua moralidade impresso na própria natureza (JGB/BM 9, KSA 5.21-22). Para comprovar seu argumento, Nietzsche dirige uma exortação aos estoicos: "Imaginem um ser tal como a natureza, desmedidamente pródigo, indiferente além dos limites, sem intenção ou consideração, sem misericórdia ou justiça, fecundo, estéril e incerto ao mesmo tempo [...]". (JGB/ BM 9, KSA 5.21-22) São vigorosas palavras de advertência, em especial para alguém que espera encontrar na natureza um guia, padrão, ou medida para conduzir vida humana. Mas em que pese o vigor dessas palavras, Nietzsche parece acreditar que, em alguns casos, podemos honrar a natureza compreendendo a sua ilimitada

7 Cf. PIPPIN, R. "Lightning and Flash, Agent and Deed (GM I 6-17), in ACAMPORA, C. D. (org.), Nietzsche's On the Genealogy of Morals: Critical Essays. Lanham, MD: Rowman \& Littefield, 2006, p. 133-137; HATAB, L. Nietzsche’s On the Genealogy of Morality, Cambridge: Cambridge University Press, 2008, p. 208-09. 
indiferença como hospitaleira (a palavra é minha, não dele) a determinadas articulações do esforço humano. A natureza pode não ser nossa patroa nem nossa amiga, é verdade, mas tampouco é nossa nêmesis ou nosso flagelo. Esperar muito pouco da natureza é tão completamente equivocado (e narcisista) quanto esperar demais dela. Nietzsche, ao que parece, contempla a indiferença da natureza como compatível com (ou, de certo modo, como não incompatível com) o florescimento do propósito e desígnio humanos — à medida que, de fato, possamos estar inclinados a atribuir finalidade e desígnio à natureza. $\mathrm{O}$ truque, é claro, é fazê-lo de um modo que não limite a natureza ao modelá-la ao propósito e desígnio humanos $^{8}$ (isto é, ao cognitivo, deliberativo, teleológico). Ao delinear um curso médio entre o antropomorfismo naïve dos estoicos e o niilismo de seus contemporâneos, Nietzsche, aparentemente, esperava desenvolver um modelo de natureza que nos permitisse apreciá-la como propositada em seus próprios termos.

Penso que é nesse sentido, limitado, que Nietzsche via a natureza como guia ou padrão a que o realista político pode recorrer. Em uma de suas mais célebres afirmações a respeito, com base em sua admiração pelas sociedades aristocráticas que impõem um rígido sistema de castas, ele enuncia:

A ordem de castas, a lei suprema, dominante, é apenas a sanção de uma ordem natural, de leis naturais de primeira categoria, sobre as quais nenhum arbítrio, nenhuma "ideia moderna" tem poder [...] A natureza, e não Manu, é que separa os predominantemente espirituais, os predominantemente fortes em músculo e temperamento, e os que não se destacam nem de uma maneira nem de outra, os medíocres - estes sendo o grande número, e os dois primeiros, os seletos (AC/AC 57, KSA 6.241-244).

8 Quanto a esse aspecto estou de acordo com RICHARDSON, J. Nietzsche's New Darwinism. Oxford: Oxford University Press, 2004, p. 11-15. 
Como a passagem confirma, o legislador sábio (ou seja, Manu) concebe políticas, constituições e castas com base no que a natureza revela para ele. Contudo, o que isso implica não está de todo claro. Aqui, Nietzsche pode ter a intenção de sugerir que algum tráfico limitado de antropomorfismos pode simplesmente ser o preço a se pagar se desejamos receber sugestões, como deveríamos, da natureza. Em todo caso, esse tipo de enunciado é relevante para os propósitos desse ensaio, pois na Genealogia da moral, Nietzsche atribui à natureza a tarefa [Aufgabe] de cultivar um animal capaz de fazer promessas (GM/GM II 1, KSA 5.291-292). Creio que ao descrever a natureza como orientada para tarefas ele intenta iluminar o único sentido não humano pelo qual da natureza se pode dizer que manifesta propósito e desígnio?.

\footnotetext{
Abstract: The paper aims to inquire the presence of a political realism in Nietzsche's thought, as well as examining the relation between this realism and a model of nature proposed by the philosopher.

Keywords: politics - decadence - modernity - realism
}

\section{referências bibliográficas:}

ACAMPORA, C. D. “On Sovereignty and Overhumanity: Why It Matters How We Read Nietzsche's Genealogy II: 2", in: ACAMPORA, C. D. (org.), Nietzsche's On the Genealogy of Morals: Critical Essays. Lanham, MD: Rowman \& Littlefield, 2006, p. 147-162.

CONWAY, D. "How We Became What We Are: Tracking the 'Beasts of Prey", in: ACAMPORA, C. D. (org.), Nietzsche's On the Genealogy of Morals: Critical Essays. Lanham, MD: Rowman \& Littlefield, 2006, p. 305-320.

9 Também aqui sigo a interpretação proposta por RICHARDSON, J., op. cit. 
CONWAY, D. Nietzsche's On the Genealogy of Morals: A Reader's Guide. London: Continuum Books, 2008.

DELEUZE, G. / GUATTARI, F. Anti-Oedipus: Capitalism and Schizophrenia. Trad. Robert Hurley, Mark Seem, Helen R. Lane. Minneapolis: University of Minnesota Press, 1983.

DETWILER, B. Nietzsche and the Politics of Aristocratic Radicalism. Chicago: University of Chicago Press, 1982.

HATAB, L. A Nietzschean Defence of Democracy. Chicago: Open Court, 1995.

HATAB, L. Nietzsche's On the Genealogy of Morality. Cambridge: Cambridge University Press (as citações são feitas da cópia corrigida da prova de prelo), 2008.

JANAWAY, C. Beyond Selflessness: Reading Nietzsche's Genealogy. Oxford: Oxford University Press, 2007.

LAMPERT, L. Nietzsche's Task: An Interpretation of Beyond Good and Evil. New Haven: Yale University Press, 2001.

LEITER, B. Nietzsche on Morality. London: Routledge, 2001.

MIGOTTI, M. "Slave Morality, Socrates, and the Bushmen: A Critical Introduction to On the Genealogy of Morality, Essay I", in: ACAMPORA, C. D. (org.) Nietzsche's On the Genealogy of Morals: Critical Essays. Lanham, MD: Rowman \& Littlefield, 2006, p. 109-130.

NIETZSCHE, F. Obras incompletas. Trad. Rubens Rodrigues Torres Filho. São Paulo: Nova Cultural, 1996 (Col. "Os Pensadores").

. Além do bem e do mal. Trad. Paulo César Souza. São Paulo: Cia das Letras, 1996.

- A gaia ciência. Trad. Paulo César Souza. São Paulo: Cia das Letras, 2001.

. O anticristo. Trad. Paulo César Souza. São Paulo: Cia das Letras, 2007.

OWEN, D. Nietzsche, Politics and Modernity. London: Sage Publications, 1995.

Nietzsche’s Genealogy of Morality. Stocksfield: Acumen Publishing, 2007.

PIPPIN, R. "Lightning and Flash, Agent and Deed (GM I 6-17), in ACAMPORA, C. D. (org.), Nietzsche's On the Genealogy of Morals: Critical Essays. Lanham, MD: Rowman \& Littefield, 2006, p. 131-145.

RICHARDSON, J. Nietzsche's New Darwinism. Oxford: Oxford University Press, 2004.

RIDLEY, A. Nietzsche’s Conscience: Six Character Studies from the Genealogy. Ithaca, NY: Cornell University Press, 1998.

RISSE, M. "The Second Treatise in On the Genealogy of Morality: Nietzsche on the Origin of the Bad Conscience”, in: European Journal of Philosophy, 9, I, 1994, p. 55-81.

SCHACHT, R. "Of Morals and Menschen”, in: Richard Schacht (ed.), Nietzsche, Genealogy and Morality. Berkeley, CA: University of California Press, 1994, p. 427-448.

SHAPIRO, G. Nietzschean Narratives. Bloomington, IN: Indiana University Press, 1998.

38 | cadernos Nietzsche 32, 2013 
SHAW, T. Nietzsche's Political Skepticism. Princeton, NJ: Princeton University Press, 2007.

SIEMENS, H. "Nietzsche contra Liberalism on Freedom", in Keith Ansell Pearson (org.), A Companion to Nietzsche. London: Blackwell Publishing, 2006, p. 437-454.

TONGEREN, P. van. Reinterpreting Modern Culture: An Introduction to Friedrich's Nietzsche’s Philosophy. West Lafayette, IN: Purdue University Press, 2000.

WARREN, M. Nietzsche and Political Thought. Cambridge, MA: MIT Press, 1988.

WHITE, R. Nietzsche and the Problem of Sovereigny. Champaign, IL: University of Illinois Press, 1997.

Artigo recebido em 30/12/2012. Artigo aceito para publicação em 10/02/2013. 